\title{
Are Midwestern fish retailers willing to pay more for regionally grown fresh-on-ice fish?
}

\author{
Rejeana M. Gvillo ${ }^{1^{*}}$, Kwamena Quagrainie ${ }^{2}$, Nicole Olynk ${ }^{2}$, Jennifer Dennis ${ }^{2}$ \\ ${ }^{1}$ Department of Agricultural Economics, Texas A\&M University, College Station, USA; \\ *Corresponding Author: rgvillo@tamu.edu \\ ${ }^{2}$ Department of Agricultural Economics, Purdue University, West Lafayette, USA
}

Received 9 April 2013; revised 10 May 2013; accepted 1 June 2013

Copyright (C) 2013 Rejeana M. Gvillo et al. This is an open access article distributed under the Creative Commons Attribution License, which permits unrestricted use, distribution, and reproduction in any medium, provided the original work is properly cited.

\begin{abstract}
The fish and seafood market in the Midwestern region of the United States is currently dominated by frozen products. Fish producers in the region may be able to market their products as fresh, regionally grown and farmed fish. Fish producers may be able to supply fresh fish products that have not been previously frozen but preserved fresh with ice. The study examined retailers' willingness to pay more for Midwestern fresh fish adopting the literature on consumers' willingness to pay for market services or products, assuming that retailers understand their customers, and that they are able to add any premiums paid for to their retail prices. The overall probability of retailers paying more for regionally grown fresh-on-ice fish is low though consistency in supply and sourcing out of state positively affected the probability to pay more. In spite of these positive factors on willingness to pay more for Midwestern fresh-on-ice fish, Midwestern fish producers would probably remain non-competitive in the fresh-on-ice fish market in the short and medium term, and should continue to focus on the live market.
\end{abstract}

Keywords: Fresh Fish; Midwest; Willingness to Pay; Ordered Probit

\section{INTRODUCTION}

Since 1980, per capita fish consumption has increased by $26.4 \%$, with the majority of consumption being fresh and frozen fish products (Figure 1) ${ }^{1}[1]$. Fish and sea-

\footnotetext{
${ }^{1}$ Other types of fish products include canned and cured; see http://www.st.nmfs.noaa.gov/st1/fus/fus09/08 perita2009.pdf for a complete listing of consumption.
}

food imports have increased since 1989 [1]. With this increase in fish supply, consumption, and expenditures, retailers may be interested in offering more varieties of fish and seafood products to their customers.

The fish and seafood market in the Midwestern (MW) region of the United States (US) is currently dominated by frozen products, and MW fish producers may be able to include additional products from the region-fresh, regionally grown and farmed fish. In particular, fish producers may be able to supply fresh fish products that have not been previously frozen but preserved fresh with ice. Most of the fish currently produced in the Midwest is sold live to ethnic markets [2].

MW fish farmers grow tilapia and trout, as well as other species such as catfish, hybrid striped bass, and yellow perch [3]. The 2007 Census of Agriculture [4] reported an increase in total MW food fish farms from 276 in 2005 [3] to 458 in $2007^{3}$ as well as an increase in sales from \$12.9 million in 2005 [3] to $\$ 24.3$ million $2007^{4}[1]$.

Besides trout, which is grown exclusively outdoors in raceways in the Midwest, the other fish species are mostly grown indoors in a controlled environment. This makes the costs of production relatively higher than the same fish species grown in outdoor ponds and cages. Studies have suggested that the cost of production from indoor operations could be as much as $2-3$ times that of outdoor production $[5,6]$. Most of the catfish and tilapia products currently available in the Midwest are sourced from the southern states where they are grown outdoors. The empirical question then is how much more are fish retailers in the MW willing to pay per pound for MW fresh-on-ice fish than for similar products from other

\footnotetext{
${ }^{2}$ The twelve states included in the MW region for the purpose of this study are: Iowa, Illinois, Indiana, Kansas, Michigan, Minnesota, Missouri, Nebraska, North Dakota, Ohio, South Dakota, and Wisconsin.

${ }^{3}$ All 12 states combined.

${ }^{4}$ All 12 states combined.
} 


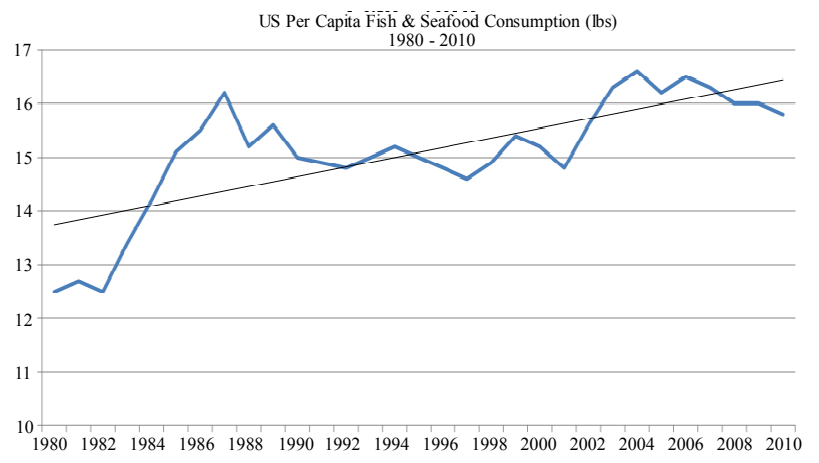

Figure 1. US per capita fish \& seafood consumption (lbs) (Source: NOAA, Fisheries of the United States, 2011).

sources outside the MW, under the assumption that retailers can pass on the additional purchase price to shoppers/consumers? It is also assumed that retailers know their customers well and their ability to pay for seafood products.

Several studies have shown that consumers are willing to pay a premium for regionally grown products. Willingness to pay is usually assessed for product attributes, which include origin. For instance, [7], focusing on labels that would attract a premium for potatoes, found that "Colorado grown" labels carried a higher premium (10\%) than organic and GMO-free attributed labels for locally grown Colorado potatoes. A study on willingness to pay for blueberry jam attributes that included organic, sugarfree, and locally produced in Kentucky found that consumers were willing to pay positive amounts for Kentucky grown blueberry jam [8]. Another study explored the potential for differentiation in fresh produce and found that when comparing two products that were harvested on the same day (yesterday), consumers will choose the local product more often [9].

Besides being local, MW fish products have many other attributes which consumers may place value on. For instance, previous studies have reported the importance of freshness and the high value consumers placing on fresh seafood products in their purchase decisions [2, 10-15]. A study focusing on US grown catfish conducted by [10] reported that customers who bought fresh catfish had a significantly higher probability of purchasing it more often than frozen catfish. The authors also reported that the origin of catfish has a significantly greater influence on frequency of catfish purchase.

Other characteristics that are relevant to decisions to purchase a fish product may include supply consistency, seasonality, species, cuts, product condition (fresh, frozen, value added), and packaging. Unlike marine fish products, farm produced fish products can be available year round, suggesting potential for supply consistency. [14] found that about $46 \%$ of live-seafood customers felt that year round supply of fish was very important. Like- wise, [10] noted that a year round supply of fresh catfish products in retail outlets was essential. The literature suggests that winter supplies of live-fish are limited due to weather conditions, resulting in higher prices for fresh fish in the winter months compared to the summer months [16].

Fish products are available in many varieties including whole, dressed whole, steaks, fillets, and various other forms (nuggets). It is reported that $19.38 \%$ of US production sales of fresh and frozen fish were in steak or fillet form and of the 507.6 million pounds of fresh and frozen fillets and steaks sold in 2009, more than 494.2 million pounds were sold as fillets [1]. It is reported that frozen fillets were the most important product of the catfish industry and that they were the fastest growing segment of tilapia imports [17]. Fillets are a popular cut of freshwater fish and contribute vastly to US freshwater fish sales.

The study of retailers' willingness to pay more for Midwestern fresh fish adopts the literature on consumers' willingness to pay for market services or products, assuming that retailers understand their customers, and that they are able to add any premiums paid for Midwestern fresh fish to their retail prices. The objective of this study is to assess the probability of a retailer willing to pay more for regionally grown fresh fish on ice. If fish retailers are willing to pay more for locally sourced fish products, this could incentivize fish producers in the MW to increase production. Specifically, this study examines retailers' willingness to pay more for tilapia, catfish, trout, and yellow perch grown in the MW region of the US.

\section{DATA \& METHODS}

\subsection{Data}

A survey was developed to gather information regarding a retailer's willingness to pay for regionally grown fresh fish. Surveys were administered throughout the 12 states in the MW region including Iowa, Illinois, Indiana, Kansas, Michigan, Minnesota, Missouri, North Dakota, Nebraska, Ohio, South Dakota, and Wisconsin. Three methods of survey administration were used including 1) mailing 2) telephone contact and 3) in person. Data were collected in 2010.

The Chain Store Guide database provided a list of retailers and specialty markets that sold fish (fresh or frozen) in the selected states. A total of 564 samples were identified from the database. Three weeks after the initial mailing to all 564 potential respondents, a follow-up survey was mailed to non-respondents. Selected cities or towns with a high number of retailers in the region were chosen to be visited in-person for a follow-up survey. These cities included Cincinnati, Columbus, and Cleveland in Ohio, Detroit, Ann Arbor, and Troy in Michigan, 
Indianapolis and Fort Wayne in Indiana, Chicago in Illinois, and Milwaukee and Madison in Wisconsin. In total, the number of completed usable surveys was 66 out of the 564 respondents contacted, representing a $12.31 \%$ response rate.

Four fish species grown in the MW region were included in the survey: catfish, tilapia, trout, and yellow perch. The species most popular amongst retailer sales in order of popularity, were tilapia, catfish, trout, yellow perch (Table 1). Both tilapia and catfish are in the top ten of domestically consumed seafood species, and are ranked 5th and 6th, respectively [1]. The summary statistics of the data utilized in this study are provided in Table 2.

The data used came from 10 of the 12 states as Iowa and North Dakota had no usable data points. Of the 66 returned surveys, approximately $35 \%$ of retailers' sales were freshwater finfish, $38 \%$ of retailers sold more than 400 pounds of fillets a week, and retailers had an average of 4.30 fresh fish deliveries per week. Retailers indicated that fresh fish was the most customer preferred product compared to frozen fish and value added fish (marinated, stuffed, etc). Thirty-eight retailers had fresh fish suppliers located only in-state or only out-of-state. More than $50 \%$ of respondents were not willing to pay extra for regionally grown fresh fish. However, all four species had a positive mean willingness to pay. The average willingness to pay values were: $\$ 0.38$ more for tilapia, $\$ 0.34$ more for yellow perch, $\$ 0.30$ more for catfish, and $\$ 0.29$ more for trout (see Table 3 for percentages of each category).

Other data collected with the survey, while important,

Table 1. Rankings of each species (low is more popular).

\begin{tabular}{ccccc}
\hline & Average & Min. & Max. & Obs \\
\hline Tilapia & 1.47 & 1 & 6 & 64 \\
Catfish & 2.21 & 1 & 7 & 61 \\
Trout & 3.12 & 1 & 7 & 57 \\
Yellow Perch & 3.40 & 1 & 8 & 48 \\
\hline
\end{tabular}

Table 2. Summary statistics for ordered probit model variables.

\begin{tabular}{ccccc}
\hline & Avg & SD & Min & Max \\
\hline Percentage of freshwater finfish sold & 0.35 & 0.19 & 0 & 0.90 \\
Sells more than 400 lbs of fillets per week & 0.38 & 0.49 & 0 & 1 \\
Deliveries per week & 4.30 & 1.84 & 0 & 8 \\
Fresh preference & 0.86 & 0.35 & 0 & 1 \\
Out state suppliers only & 0.28 & 0.45 & 0 & 1 \\
In state suppliers only & 0.17 & 0.38 & 0 & 1 \\
\hline
\end{tabular}

Table 3. Percentage willingness to pay for each species.

\begin{tabular}{cccc}
\hline & $\$ 0$ & $\$ 0.50$ & $>\$ 0.50$ \\
\hline Catfish & $57 \%$ & $32 \%$ & $12 \%$ \\
Tilapia & $51 \%$ & $32 \%$ & $17 \%$ \\
Trout & $57 \%$ & $29 \%$ & $13 \%$ \\
Yellow Perch & $57 \%$ & $26 \%$ & $17 \%$ \\
\hline
\end{tabular}

was not used in the model such as a series of questions regarding selected characteristics and their ranked importance. The majority of respondents indicated "very important characteristics" being freshness (96\%), overall appearance $(93 \%)$, and price $(57 \%)$. The following characteristics were regarded as important by respondents: Supply consistency $(50 \%)$, type of cut $(52 \%)$ and sustainability (44\%); meanwhile, characteristics that respondents indicated as not important included fish grown in the MW region (59\%), organically grown fish (74\%), and hormone free fish (44\%). Forty retailers indicated they would purchase tilapia if it was raised in the MW, 26 would purchase catfish, 25 would purchase yellow perch, and 22 would purchase trout. The top fish species sold by retailers were salmon, tilapia, catfish, and cod, respectively. These species are among the top ten species consumed in the US reported by [1].

\subsection{Method}

In examining the willingness of retailers in the MW market to pay more for regionally (MW) grown fresh fish, this study adopts the literature on consumers' willingness to pay for market services or products. Willingness to pay is usually expressed as a function of product attributes, characteristics of the consumer, and other factors thought to influence the consumer's choice [18]. In general, willingness to pay models is specified with limited dependent variable or latent variable approaches [19]. This is because the dependent variable, $Y$, either has a restrictive value range (limited) or is an unobserved (latent) variable. To illustrate the options for a fish retailer's willingness to pay for regionally grown fresh fish on ice, the dependent variable $(Y)$ takes the following values: $Y$ $=0$ if not willing to pay more per pound; $=1$ if willing to pay $\$ 0.50$ more per pound; $=2$ is willing to more than $\$ 0.50$ per pound. Following this format, the probability of having a willingness to pay between defined levels is:

$$
\begin{aligned}
& \operatorname{Pr}\left(\mathrm{WTP}^{L}<\mathrm{WTP} \leq \mathrm{WTP}^{U}\right) \\
= & \operatorname{Pr}\left(X^{\prime} \beta+\varepsilon \leq \gamma^{U}\right)-\operatorname{Pr}\left(X^{\prime} \beta+\varepsilon<\gamma^{L}\right)
\end{aligned}
$$

where $\operatorname{Pr}($.$) is the probability operator, \mathrm{WTP}^{L}$ and $\mathrm{WTP}^{U}$ are lower and upper limits of willingness to pay that one is interested in, and $\gamma^{U}$ and $\gamma^{L}$ are threshold changes in utility consistent with the lower and upper ranges of 
willingness to pay [18].

Fish retailers have three alternatives for a value of willingness to pay. This order is an intrinsic order resulting in using an ordered qualitative response model, which allows the willingness to pay model to be written using a latent variable as follows:

$$
\mathrm{WTP}_{i}=X_{i}^{\prime} \beta+\varepsilon_{i}
$$

where $X_{i}$ is a vector of variables thought to influence willingness to pay, $\beta$ is a vector of parameters reflecting the relationship between willingness to pay and variables in $X$, and $\varepsilon_{i}$ is an independently and identically distributed error term with mean zero and variance one. If the willingness to pay of an individual falls within a particular range, their willingness to pay is assigned a numerical value; this value reflects the category in which their unobserved willingness to pay lies.

To estimate the willingness to pay of fish retailers in the MW for fresh fish on ice, an ordered probit model is used, which allows for the calculation of predicted probabilities for each willingness to pay category and provides the marginal effects. The general format of a probit model is as follows:

$$
\operatorname{Pr}(Y=i \mid x)=\int \phi(t) \mathrm{d} t=\Phi\left(x^{\prime} \beta\right) \text { for } i=0,1,2
$$

The function $\phi($.$) is a commonly used notation for the$ standard normal distribution function [20] which is defined as:

$$
\Phi(z)=(1 / \sqrt{2} \pi) e^{\left(-z^{2} / 2\right)}
$$

The ordered probit model for a fish retailer's willingness to pay more for a MW produced fish is specified as follows:

$$
\begin{aligned}
P_{i}(\mathrm{WTP})= & \text { Con }+\beta_{1}(\mathrm{FFFF})+\beta_{2}(\text { Fillets }) \\
& +\beta_{3}(\text { Deliveries })+\beta_{4}(\text { Fresh }) \\
& +\beta_{5}(\text { Outstate })+\beta_{6}(\text { Instate })+\varepsilon_{\mathrm{i}}
\end{aligned}
$$

where $P_{i}(\mathrm{WTP})$ is $P_{i}\left(Y_{i}=0\right)$ if the retailer is not willing to pay more $(\$ 0.00)$ for MW grown fresh-on-ice fish for species $i, P_{i}\left(Y_{i}=1\right)$ if the retailer is willing to pay up to $\$ 0.50$ more per pound for species $i$, and $P_{i}\left(Y_{i}=2\right)$ if the retailer is willing to pay over $\$ 0.50$ more per pound for species $i$.

The dependent variables were selected based on previous studies. "Con" is constant equal to 1 , and "FFFF" is the average percentage of freshwater finfish sales when compared to all fresh fish and seafood sales. Tilapia, catfish, trout, and yellow perch are finfish grown in the MW, and it is postulated that if retailers sell more finfish compared to shellfish, they may be willing to pay more for MW finfish. "Fillet" is a binary variable that is equal to 1 if the retailer sells more than 400 pounds of fresh fish and seafood fillets per week (0 otherwise). As alluded earlier, fillets are a popular cut of freshwater fish and contribute vastly to US freshwater fish sales; however, fillets are mostly sold in frozen form. There is no a priori expectation of the direction for this variable. "Deliveries" is the number of deliveries of fresh fish per week, and it is expected to have a positive sign to reflect preference for consistency in supply. "Fresh" is also a binary variable equal to 1 if the retailer indicated that customers prefer fresh fish over frozen fish and value added ( 0 otherwise), and it is expected to have a positive sign. "Outstate" is equal to 1 if the retailer's fish suppliers are from out of state only, and "Instate" is equal to 1 if the retailer's fish suppliers are only from in-state. There are no a priori expectations of the direction for these source variables.

The equation was estimated for four species including tilapia, catfish, trout, and yellow perch. When interpreting ordered probit model results, the coefficients should be treated with caution. Because of the independent variable $(Y)$ being a label for unordered, non-quantitative outcomes, there is no conditional mean function [21]. Rather, the marginal effects of the model are useful for interpreting the various parameters. For each explanatory variable, the sum of the marginal effects for the willingness to pay categories will be zero. For continuous variables, marginal effects are interpreted as a one unit change in the explanatory variable resulting in an increase or decrease in the predicted probability equal to the size of the marginal effect [18]. For binary variables, the marginal effect is the change in predicted probability based on whether a respondent falls into that category or not; marginal effects show the change in the predicted probability for each willingness-to-pay class for an average retailer, according to the variable being considered [18].

\section{RESULTS}

The ordered probit model predicted the number of 0's (not willing to pay), 1's (willing to pay up to $\$ 0.50$ more) and 2's (willing to pay over $\$ 0.50$ more). The percent correctly predicted (PCP) for each species is provided in each Tables $\mathbf{4}$ and $\mathbf{5}$ for each species. The lowest PCP species was catfish which was $54.55 \%$ PCP while the highest PCP was trout and yellow perch at $59.09 \%$.

Results for tilapia are presented in Table 4. Tilapia, the most preferred species in the study, had three statistically significant variables. "Deliveries per week" was positive, suggesting that as the number of deliveries per week increases, retailers are willing to pay more for MW grown fresh tilapia. The "fresh preference" variable was negative, unexpected, and counter intuitive. There is probably some underlying issue which is not captured in the model. It must be pointed out that imported tilapia are in 
Table 4. Ordered probit results for tilapia and catfish.

\begin{tabular}{ccccccc}
\hline & \multicolumn{3}{c}{ Tilapia } & \multicolumn{3}{c}{ Catfish } \\
\hline FFFF & -1.11 & 0.93 & 1.16 & -1.09 & 0.98 & 1.16 \\
Fillets & 0.52 & 0.32 & 0.36 & 0.17 & 0.33 & 0.38 \\
Deliveries & $0.24^{* *}$ & 0.10 & 0.13 & $0.23^{* *}$ & 0.10 & 0.14 \\
Fresh & $-0.82^{*}$ & 0.44 & 0.56 & $-1.09^{* *}$ & 0.45 & 0.54 \\
OutState & $0.66^{*}$ & 0.36 & 0.45 & 0.31 & 0.37 & 0.46 \\
InState & 0.16 & 0.40 & 0.52 & 0.39 & 0.40 & 0.52 \\
Constant & -0.23 & - & - & -0.14 & - & - \\
PCP & $57.58 \%$ & - & - & $54.55 \%$ & - & - \\
\hline *** ** and ${ }^{*}$ indicate statistical significance at the $1 \%, 5 \%$, and $10 \%$ respec- \\
tively.
\end{tabular}

Table 5. Ordered probit results for trout and yellow perch.

\begin{tabular}{cccccccc}
\hline & \multicolumn{3}{c}{ Trout } & \multicolumn{4}{c}{ Yellow Perch } \\
\hline FFFF & 0.20 & 0.93 & 0.10 & -0.35 & 0.93 & 1.03 \\
Fillets & 0.04 & 0.33 & 0.37 & 0.07 & 0.33 & 0.38 \\
Deliveries & $0.31^{* * *}$ & 0.10 & 0.15 & $0.17^{*}$ & 0.10 & 0.14 \\
Fresh & -0.13 & 0.46 & 0.96 & 0.01 & 0.45 & 1.00 \\
OutState & $0.88^{* *}$ & 0.37 & 0.45 & $0.97^{* *}$ & 0.37 & 0.46 \\
InState & 0.07 & 0.41 & 0.53 & 0.51 & 0.40 & 0.51 \\
Constant & -1.78 & - & - & $-1.20^{*}$ & - & - \\
PCP & $59.09 \%$ & - & - & $59.09 \%$ & - & - \\
\hline *** ** \\
tively.
\end{tabular}

abundance and very cheap. "Outstate" was positive which suggests that if a retailer's supply of fresh fish comes from outside the state, the retailer is willing to pay more for fresh tilapia. Perhaps some retailers cannot get the supply of fresh tilapia they want from within the state and are therefore forced to outsource some supply. Most tilapia comes from out of the state as the MW farms are not yet producing large quantities.

Catfish (see Table 4), the second most popular species, had two statistically significant variables including the number of "deliveries per week", which was positive and "fresh preference", which was negative. Like tilapia (Table 4), the negative sign is unexpected. Fresh catfish can be obtained relatively cheaper from southern states where catfish is grown exclusively; it could be that retailers do not want to pay more for fresh, MW catfishthey are already able to get the fresh quantities needed.
The results for trout and yellow perch are presented in Table 5. Trout and yellow perch are the third and fourth most popular species, respectively, and each had the number of "deliveries per week" and fish deliveries from "out of state" being positive. Regarding the effect of the "out of state" variable, perhaps because MW states do not produce enough quantities of these species, as with tilapia and catfish, retailers source these two fish products from out of state.

The marginal effects of the explanatory variables are provided in Tables 6-9 for the four species examined. A positive sign denotes an increase in marginal utility while a negative sign denotes a decrease in marginal utility [10]. All four species had a larger magnitude of marginal effect for $\$ 0.00$ willingness to pay when compared to willingness to pay up to $\$ 0.50$ more and willingness to pay more than $\$ 0.50$ for all six explanatory variables.

For tilapia (Table 6), catfish (Table 7), trout (Table 8), and yellow perch (Table 9), the marginal effect of "deliveries" changed from negative to positive as willingness to pay amounts increased. For all four species, the magnitude of the marginal effect was larger for willingness to pay $\$ 0.00$ than the effect on positive willingness to pay. For example, in the tilapia model (Table 6), the

Table 6. Marginal effects for tilapia.

\begin{tabular}{cccc}
\hline Tilapia & $\mathrm{WTP}=\$ 0.00$ & $\mathrm{WTP}=\$ 0.50$ & $\mathrm{WTP} \geq \$ 0.50$ \\
\hline Actual & $81.25 \%$ & $36.36 \%$ & $33.33 \%$ \\
Predicted & $57.75 \%$ & $53.33 \%$ & $66.67 \%$ \\
FFFF & 0.44 & -0.18 & -0.26 \\
Fillets & -0.10 & 0.04 & 0.06 \\
Deliveries & -0.09 & 0.04 & 0.06 \\
Fresh & 0.30 & -0.06 & -0.24 \\
Outstate & -0.25 & 0.08 & 0.17 \\
Instate & -0.06 & 0.02 & 0.04 \\
\hline
\end{tabular}

Table 7. Marginal effects for catfish.

\begin{tabular}{cccc}
\hline Catfish & WTP $=\$ 0.00$ & WTP $=\$ 0.50$ & WTP $\geq \$ 0.50$ \\
\hline Actual & $81.08 \%$ & $27.27 \%$ & $0.00 \%$ \\
Predicted & $62.50 \%$ & $35.29 \%$ & $0.00 \%$ \\
FFFF & 0.43 & -0.27 & -0.16 \\
Fillets & -0.07 & 0.04 & 0.03 \\
Deliveries & -0.09 & 0.06 & 0.03 \\
Fresh & 0.41 & -0.16 & -0.25 \\
Outstate & -0.12 & 0.07 & 0.05 \\
Instate & -0.16 & 0.09 & 0.07 \\
\hline
\end{tabular}


Table 8. Marginal effects for trout.

\begin{tabular}{cccc}
\hline Trout & $\mathrm{WTP}=\$ 0.00$ & $\mathrm{WTP}=\$ 0.50$ & $\mathrm{WTP} \geq \$ 0.50$ \\
\hline Actual & $86.84 \%$ & $10.53 \%$ & $44.44 \%$ \\
Predicted & $60.00 \%$ & $40.00 \%$ & $66.67 \%$ \\
FFFF & -0.08 & 0.04 & 0.04 \\
Fillets & -0.02 & 0.01 & 0.01 \\
Deliveries & -0.12 & 0.07 & 0.06 \\
Fresh & 0.05 & -0.03 & -0.03 \\
Outstate & -0.34 & 0.14 & 0.20 \\
Instate & -0.03 & 0.01 & 0.01 \\
\hline
\end{tabular}

Table 9. Marginal effects for yellow perch.

\begin{tabular}{cccc}
\hline Yellow Perch & $\mathrm{WTP}=\$ 0.00$ & $\mathrm{WTP}=\$ 0.50$ & $\mathrm{WTP} \geq \$ 0.50$ \\
\hline Actual & $91.89 \%$ & $5.56 \%$ & $36.36 \%$ \\
Predicted & $59.65 \%$ & $50.00 \%$ & $57.14 \%$ \\
FFFF & 0.14 & -0.06 & -0.08 \\
Fillets & -0.03 & 0.01 & 0.02 \\
Deliveries & -0.07 & 0.03 & 0.04 \\
Fresh & -0.00 & 0.00 & 0.00 \\
Outstate & -0.37 & 0.11 & 0.26 \\
Instate & -0.20 & 0.07 & 0.13 \\
\hline
\end{tabular}

marginal effect of $-9 \%$ on willingness to pay $\$ 0.00$ is greater than the $4 \%$ effect on willingness to pay up to $\$ 0.50$, and $6 \%$ effect on willingness to pay over $\$ 0.50$ more. In other words, with more deliveries per week, the probability of retailers' willing to pay $\$ 0.00$ is significantly reduced while the probability of paying more increases.

The "fresh" variable for tilapia, catfish, and trout, had positive and relatively larger marginal effects for the willingness to pay $\$ 0.00$, but negative effects on the other two categories. This suggests that the probability of retailers' willingness to pay more for Midwestern fresh tilapia, catfish, and trout is significantly low, indicating there is no room for Midwestern fish farmers to attract premiums for these products.

The remaining variables including fillets, out-of-state, and in-state had similar marginal effects for tilapia (Table 6), catfish (Table 7), trout (Table 8), and yellow perch (Table 9). The marginal effects changed from negative for zero amounts of willingness to pay to positive for willingness to pay amounts above zero. This suggests that retailers are more likely to be willing to pay more for regionally grown fish as fillet sales increase.

About $95 \%$ of retailers reported price as being "very important" and "important" to their purchase decisions. Given the relatively larger and stronger marginal effects for willingness to pay $\$ 0.00$ compared to positive willingness to pay more values, it suggests that fish retailers are not prepared to pay premiums fresh-on-ice fish from the Midwest. Midwest fish farmers would probably remain non-competitive if they venture into value added processing for fresh fish on ice, and the live market would continue to be a better market outlet for their products.

\section{CONCLUSIONS}

For the four species examined, the overall probability of paying more for regionally grown fish is low; more than half of the retailers in this study are not willing to pay any more for Midwestern fresh fish than they are currently paying for fresh fish. All four species had some retailers indicating positive amounts of willingness to pay more per pound for regionally grown fish with tilapia having the highest mean willingness to pay amounts. As fresh fish deliveries increase, retailers have an increased probability of paying more, which probably reflects retailers' preferences for supply consistency. About $97 \%$ of retailers reported supply consistency as being a "very important" or an "important" characteristic. The "out of state" variable was generally positive suggesting that perhaps retailers cannot get the supply of fresh fish they want from within the state and therefore source fish products from out of state.

In spite of these positive factors affecting fish retailers' willingness to pay more for Midwestern fresh-on-ice fish, fish producers in the Midwest would probably remain non-competitive with value added processing for freshon-ice fish in the short and medium term, and they should continue to focus on the live market.

Future research could look into answering questions relating to more general origin and other labeling issues. Retailers also expressed consumer concern associated with mercury levels. Perhaps producers can take advantage of using production methods labels to market to retailers, catering to consumers' wants and needs.

\section{ACKNOWLEDGEMENTS}

This project was supported financially by the USDA-Agricultural Marketing Service's Federal-State Marketing Improvement Program (FSMIP).

\section{REFERENCES}

[1] US Department of Commerce, National Oceanic Atmospheric Association (NOAA) (2010) Fisheries of the United States.

http://www.st.nmfs.noaa.gov/st1/fus/fus09/ index.html 
[2] Quagrainie, K.K., Xing, A. and Hughes, K.G. (2011) Factors influencing the purchase of live seafood in the north central region of the United States. Marine Resource Economics, 26, 59-74.

doi:10.5950/0738-1360-26.1.59

[3] USDA, National Agricultural Statistics Service-NASS. (2005) Table 7: Food fish sales by species, by state and United States: 2005 and 1998. Census of Aquaculture. http://www.agcensus.usda.gov/Publications/2002/Aquacu $\underline{\text { lture/index.asp }}$

[4] USDA, National Agricultural Statistics Service-NASS (2007) Table 23: Aquaculture sold: 2007 and 2002. Census of Agriculture.

http://www.agcensus.usda.gov/Publications/2007/Full_Re port/Volume 1, Chapter 2 US State Level/st99 2023 023.pdf

[5] Hart, S.D., Garling, D.L. and Malison, J.A. (2006) Yellow perch (Perca flavescens) culture guide. North Central Regional Aquaculture Center (NCRAC) Culture Series \#103, Michigan State University, Lansing.

[6] Timmons, M.B. and Ebeling, J.M. (2007) Recirculating aquaculture. Northeastern Regional Aquaculture Center (NRAC) Publication \#01-007, Michigan State University, Lansing.

[7] Loureiro, M.L. and Hine, S. (2002) Discovering niche markets: A comparison of consumer willingness to pay for local (Colorado grown), organic, and GMO-free products. Journal of Agricultural and Applied Economics, 34, 477-487.

[8] Hu, W., Woods, T. and Bastin, S. (2009) Consumer cluster analysis and demand for blueberry jam attributes. Journal of Food Products Marketing, 15, 420-435. doi:10.1080/10454440802544716

[9] Darby, K., Batte, M., Ernst, S. and Roe, B. (2006) Will ingness to pay for locally produced foods: A customer intercept study of direct market and grocery store shoppers. American Agricultural Economics Association Annual Meeting, Long Beach, 23-26 July 2006, California.

[10] Kumar, G., Quagrainie, K.K. and Engle, C. (2008) Factors that influence frequency of purchase of catfish by US households in selected cities. Aquaculture Economics and Management, 12, 252-267. doi:10.1080/13657300802494297
[11] McCluskey, J.J., Grimsrud, K., Ouchi, H. and Wahl, T.I. (2005) Bovine spongiform encephalopathy in Japan: Consumers' food safety perceptions and willingness to pay for tested beef. The Australian Journal of Agricultural and Resource Economics, 49, 197-209. doi:10.1111/j.1467-8489.2005.00282.x

[12] Myers, J.J., Govindasamy, R., Ewart, J.W., Liu, B., You, Y., Purduri, V.S. and O'Dierno, L.J. (2010) Consumer analysis in ethnic live seafood markets in the northeast region of the United States. Journal of Food Products Marketing, 16, 147-165. doi:10.1080/10454440903415477

[13] Puduri, V., Govindasamy, R., Myers, J.J. and O'Dierno, L.J. (2011) Consumer attitude towards pricing of live aquatic products. Aquaculture Economics and Management, 15, 118-129. doi:10.1080/13657305.2011.573522

[14] Puduri, V., Govindasamy, R., Myers, J.J. and O'Dierno, L.J. (2010) Demand for live aquatic products in the Mid-Atlantic States: An ordered probit analysis towards consumers' preferences. Aquaculture Economics and Management, 14, 30-42. doi:10.1080/13657300903566860

[15] Quagrainie, K.K. (2006) IQF Catfish retail pack: A study of consumers' willingness to pay. International Food and Agribusiness Management Review, 9, 75-87.

[16] Zimet, D. and Zajicek, P. (2000) The market potential for live Florida food fish in the Northeastern United States. The Business of Marketing Live Aquatic Products, Annapolis, 1-4 November 2000.

[17] Harvey, D.J. (2005) US aquaculture production higher in 2005. ERS: Aquaculture Outlook LDP-AQS-21, United States Department of Agriculture, Washington DC.

[18] Cranfield, J.A.L. and Magnusson, E. (2003) Canadian consumer's willingness-to-pay for pesticide free food products: An ordered probit analysis. International Food and Agribusiness Management Review, 6, 13-30.

[19] Wooldridge, J.M. (2009) Introductory econometrics: A modern approach. South-Western Cengage Learning, Mason.

[20] Greene, W.H. (2008) Econometric analysis. Prentice Hall, Upper Saddle River.

[21] Greene, W.H. and Hensher, D.A. (2008) Molding ordered choices: A perimer and recent developments. Version 4. 